(C) 2010 IEEE. Personal use of this material is permitted. Permission from IEEE must be obtained for all other uses, in any current or future media, including reprinting/republishing this material for advertising or promotional purposes, creating new collective works, for resale or redistribution to servers or lists, or reuse of any copyrighted component of this work in other works. 


\title{
State of the art Review for Trust Maintenance in Organizations
}

\author{
Olivia Fachrunnisa ${ }^{1,2}$, Farookh Hussain ${ }^{1}$, Elizabeth Chang ${ }^{1}$ \\ ${ }^{1}$ Digital Ecosystems and Business Intelligence (DEBI) Institute, \\ Curtin University, Perth, Australia \\ ${ }^{2}$ Dept. of Management, Faculty of Economics, \\ UNISSULA, Semarang, Indonesia \\ e-mail: olivia.fachrunnisa@postgrad.curtin.edu.au \\ Farookh.Hussain, Elizabeth.Chang $\{@$ cbs.curtin.edu.au $\}$
}

\begin{abstract}
The nature of trust in business relationships is dynamic rather than static. Trust has evolutionary phases or a life cycle. This pattern of evolution can be described as building, maintaining and destroying. Building trust comes at high cost and hard effort. Therefore, once trust has been established in a business relationship, every effort must be made to maintain it. Maintaining trust can be defined as an effort to maximize the benefits of a relationship and to prevent the level of trust from decreasing to the destroying phase. Grounded in state-of-the-art literature, this paper presents current insights for the research into trust maintenance and suggests directions for future research in this field.
\end{abstract}

Keywords: Trust maintenance

\section{INTRODUCTION}

Trust research has increasingly attracted growing interest from academics and practitioners, due to its importance and due to the increasing number of business relationship such as strategic alliances, joint ventures, outsourcing relationships and other forms of interorganizational and intra-organizational exchange [1-3]. However, trust has evolutionary phases. This pattern of a trust life cycle can be described as building, maintaining and destroying [4]. Initially in a relationship, both parties (trusted agent and trusting agent) enter that relationship with activities that establish a level of trust. At this stage, the trust level is zero because the interacting parties lack information about each other. As this relationship proceeds over time, if trust building actions are acceptable, the overall level of trust will remain constant with some minor variations. Both parties then should agree to maintain their level of trust. If, however, they do not agree to maintain the level of trust, the trust will be destroyed. Therefore, the level of trust rapidly decreases to a lower level or may even enter the domain of distrust. In this paper, we offer a brief review of existing researches regarding trust maintenance.

Trust is said to be one party's expectation of the other party's competence, goodwill and behavior [5]. However, this definition ignores the temporal and context-specific nature of trust. Chang et al. proposed a definition of trust, which takes into account its temporal dimension [6]. They define trust as 'the belief the trusting agent has in the trusted agent's willingness and capability to deliver a mutually agreed service in a given context and in a given time slot, as expected by the trusting agent'. This definition considers the nature of trust as being dynamic rather than static. In a business context, competencies in a given context, as well as goodwill to deliver, are required in order for trust to develop. Competencies such as technical capabilities, skills and knowledge are also required for building trust in the professional setting of business exchange. Following an evolutionary process, the more we observe of these three characteristics in other parties, the more likely is our level of trust to increase or decrease. Hence, the level of trust will evolve as the parties interact and are driven by the factors mentioned above.

In the field of trust evolution research, most of the discussion focuses on ways to build and develop trust in such relationships. Some good management practices and policies have been proposed for building and developing trust. However, trust building is a gradual and incremental process. It can be easily and quickly destroyed by a single negative behavior or trustworthiness inconsistencies [4, 7]. Despite the fragility of trust, companies must carefully consider how they can better build and maintain trust to improve long-term business performance. Therefore, another objective in this paper is to discuss some theoretical approaches on how to maintain trust. In addition, we briefly review several approaches to maintaining trust.

\section{THE LIFE CYCLE OF TRUST}

The ways in which trust develops and is maintained have been recognized as critical factors in human relationships [8]. Trust will evolve and change over time in relationships as knowledge and information about other parties' trustworthiness also evolve in those relationships. Some studies have described this evolutionary pattern. For instance, Curral and Epstein divide the trust evolution pattern into three phases: developing, maintaining and 
destroying [4]. This evolutionary process is shown in fig. 1.

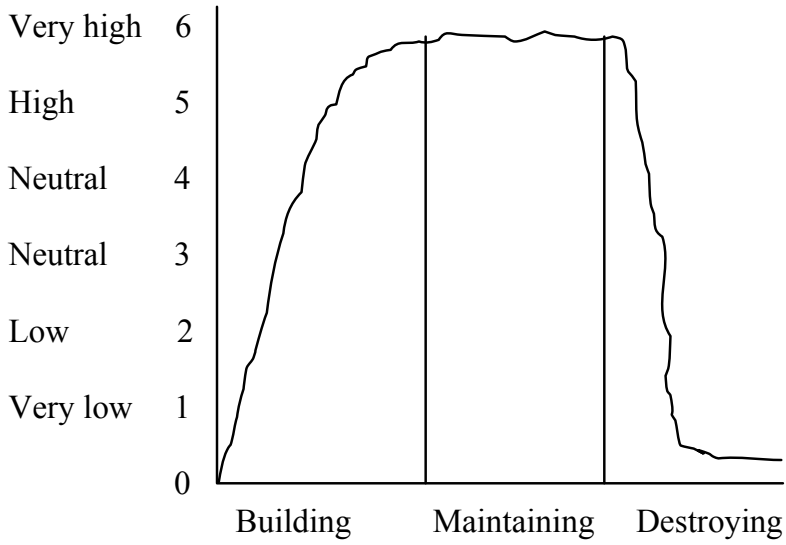

Figure 1. The pattern of trust life cycle

In the first stage of a relationship, the trust level starts from a baseline, as either trust or distrust. As the relationship proceeds over time, the trust level may increase and remain at a certain level depending upon the information and knowledge of other trustworthiness. The trust cycle then enters the maintenance stage. This stage is a very beneficial period during which the relationship between the parties is maintained, as long as neither party takes any action that will destroy the relationship. If, however, the trust level is not well maintained, the level of trust may drop quickly into the lower level or may enter the domain of distrust.

In addition, Rousseau et al. propose that in such relationships, trust changes over time [9]. Research into organizations as well as broader society indicates that a distinct pathway exists in relationships going from developing, building, declining and even resurfacing in long-standing relationships Therefore, trust is a dynamic rather than a static process, as a business relationship can also be considered as a dynamic social system.

Based on trust evolution and trust level changes over time in business relationships, Curral and Epstein argue that the most attention should be given to the maintenance phase [4]. Although the constituents may vary, trust determines the performance of most industries. Members of organizations may come and go, leaders may change, but the determinants of trust, the decision to trust and the level of trustworthiness are applicable across companies. They contend that once trust has been built, parties may actively reject evidence that the other party whom they trust is actually untrustworthy. However, this situation may make trust decrease rapidly to a lower level or even to distrust. Furthermore, they suggest that despite the fragility of organizational trust, managers must think in a systematic manner about what they can do to cultivate and maintain trust with and among the various elements in their industry and company [4].

\section{CURRENT RESEARCH ON TRUST MAINTENANCE}

Trust maintenance can be defined as an effort to keep the level of trust in a relationship stable, or even to increase it to a higher level. The existing research in trust management focuses more on building and developing the level of trust than on maintenance. Most studies offer some management practices and policies that can adopted by organizations to build and develop trust relationship either between organizations or within an organization [10-12]. However, they sometimes treat the terms 'trust formation', 'trust building', 'trust developing' and 'trust maintaining' as if these were synonymous [10, 13-15]. Therefore, much confusion exists in the current literature regarding the definitions of these terms.

In addition, there are many organizational theories that are used by scholars when suggesting good management practices for developing and maintaining trust. This theoretical approach is often the basis for methods or models of ways to build and maintain trust. In the next section, we discuss some aspects of this approach based on our review of thirteen articles (Table 1).

\section{A. Relational Signalling Theory Approach}

Relational signals play a crucial role in trust building. This theory states that in such a relationship between trustor and trustee, both parties learn about each others' trustworthiness based on behavior signals that they deliver. A trustor looks for two things in the behavior and intention of the trustee in order to discover whether the trustee is interested in maintaining the relationship. Firstly, the trustor perceives whether the behavior indicates competence to perform according to expectation (dimension of ability in trustworthiness). Secondly, a trustor looks for signs of whether the behavior of the trustee indicates an interest in maintaining the relationship in the future (intentions dimension). We call these signs as relational signals. Relational signals are 'behavioral cues that allow us to make inferences about other people's interest in maintaining a mutually rewarding social or work relationship with us' [11].

There are two forms of relational signals: positive signal and negative signal. A positive relational signal is any behavior that reassures another party (e.g. trustor) and is perceived by the second individual (e.g. trustee) as a clue that the other party wants to maintain a mutually trusting relationship. On the other hand, a negative relational signal is any behavior which makes another individual feel uncomfortable, judging others' behavior as a clue that the other party does not want to maintain a mutually benefit relationship.

This theory is based on two basic assumptions about a reciprocal process in which both parties are involved interactively in building trust [11]. Firstly, human behavior is goal-directed and any effort which explains social phenomena must consider the goals of the individual. This rationale is strongly bounded by the fact 
that the various potential goals are not all given equal consideration. Secondly, human behavior is contextdependent and guided by the normative context in which the individual is embedded. This theoretical approach has been used by Dirks [13], Six [11] and Six and George [10] to offer a model for building and maintaining organizational trust.

Dirks [13] proposed a two qualitatively-relational signal in a different theoretical perspective for building trust in a leader. This model comprises two practices and policies from a relationship-based perspective and a characterbased perspective. A relational-based perspective focuses on the nature of a leader-follower relationship and more precisely, on how the follower understands the nature of the relationship. This model deals with employee willingness to reciprocate care and consideration which a leader expresses in a relationship. On the other hand, the character-based perspective focuses on the perception of a leader's character and how it impacts on a follower's vulnerability in a hierarchical relationship. This perspective is concerned with the importance of the leader's character. The leader may have the authority to make decisions that have a significant impact on a follower's ability to achieve his or her goals.

From both of these two perspectives, trust in the leader - subordinate relationship is a psychological state experienced by both parties (leader and follower) and involves confident positive expectations about the behavior and intentions of both parties. Dirks' model [13] emphasizes that organizations must encourage leaders to show behaviors that are perceived as being trustworthy by their subordinates in some way through actions such as encouraging participative decision making and open communication, and attempting to understand individuals' explanations of the cause of events and individual perception and judgment about others.

Six [11] proposed some organizational policies for building trust based from the relational signaling perspective. Six argues that in building trust, the actions of involved parties should be guided by a stable normative frame that meets four conditions. These conditions are: suspension of all opportunistic behaviors, exchange of positive relational signals, avoidance of negative relational signals, and stimulation of frame resonance. This normative frame is suitable for building trust in a leader - subordinate relationship. The reciprocal action of exchanging positive relational signals and avoiding negative relational signals is important in order to maintain the trust level in a relationship.

Moreover, Six and Sorge [10] also used the relational signaling perspective to build a model that contains practices and policies to build, maintain and enhance trust in a leader - subordinate, and co-worker relationship. This model is a combination of four inductive activities. If an organization wants to build and maintain the level of trust among organization members, the creation of a relationship culture, facilitation of relational signaling, explicit socialization for new members and a mechanism for managing professional competencies are types of organizational policies that can be adopted by various organizations.

\section{B. Social Exchange Approach}

The social exchange approach is widely used by some scholars to develop a model for building and maintaining trust in relationships. In this approach, both parties engage in 'exchange' relationships because they expect that they will derive some benefit(s) from doing so. This involves accepting some degree of vulnerability in the hope of gaining some benefit at the discretion of another person. In a leader and co-worker relationship, perceiving other organization members to be trustworthy increases the likelihood that the trustor will engage in an exchange relationship. Presumably, individuals should be able to complete their job responsibilities more effectively when they receive valued information, knowledge, resources and so on from their leader or co-worker. Moreover, individuals who are perceived as being more trustworthy have the potential to receive more task-performance related resources from others than do individuals who are perceived to be less trustworthy. Therefore, the former will gain a performance advantage.

In addition, exchange theory explains how past behaviors in the relationship are used to diagnose trustworthiness in future exchanges. This social processbased theory also proposes that trust will develop through interaction between two parties. Hence, as trust maintenance is an activity that involves an agreement between two parties in order to maintain their trust level in a future relationship, this approach is one way of maintaining trust.

Whitener proposed an exchange framework of initiating managerial trustworthy behavior [17]. This framework consists of organizational factors, relational factors and individual factors that influence any effort to initiate trust in leaders. Some organizational strategies used to build trust in management include the establishment of an organizational structure, organizational culture and Human Resource policies and practices. The relational factors which develop from social exchange theory and relational signaling theory include such things as initial interactions, expectations, and cost of exchange; whereas individual factors that influence initiating trust in leaders are propensity to trust, self efficacy and personal values. The focus of this framework is the identification of factors that affect trustworthy behavior. Some Human Resource practices and policies in organizations such as training, reward, control and performance appraisal, may facilitate building trust in leaders or trust in higher level management. 


\section{Organizational Justice Theory}

The concept of organizational justice for maintaining organizational trust is based on the perception of fairness. Fairness and honesty are perceived by other parties as being components of trustworthiness. Three of the most commonly studied facets of organizational justice include distributive, procedural and interactional justice. Distributive justice is defined as the perceived fairness of outcomes received; procedural justice is the fairness of a company's policies and procedures used to determine one's outcomes; and interactional justice is the manner in which the reasons behind the outcome are explained. Interactional justice refers to the quality of interpersonal processes and treatment of individuals as well as the extent to which the reasons behind the outcome are explained [18].

Ferres, Connel et al [2] provide three theories as a basis of organizational practices and policies to determine trust in leaders. These theories relate to organizational support, procedural justice and transformational leadership. The authors conclude that leaders can influence trust in their relationships with subordinates in a number of ways. These include the adoption of a transformational leadership orientation, by ensuring procedural justice and supporting employees at every organizational level. Moreover, they also indicate that the formation of trust in leaders goes beyond an employee's general preference when trusting others. Managers can significantly engender trust in their relationships with subordinates in a number of ways. These include practicing transformational leadership and ensuring the adoption of practices that are both supportive and fair.

Furthermore, the empirical research conducted by Forret and Love strongly supports the notion that perceptions about distributive, procedural and interactional justice correlate to perception of co-workers [18]. The distribution of rewards, organizational policies and procedures, and interpersonal treatment by supervisors are important and relate to co-worker trust. Therefore, the authors suggest that leaders in an organization need to enhance the perception of distributive, procedural and interactional justice in the workplace if they want to build and establish trust within a leader - follower relationship.

\section{Institutional Theory Approach}

Institutional theory states that organizational structure, policies and control mechanisms should be legalized and legitimized in order to foster trust through the perception of individual and institutional legitimacy. Managers use organizational clues to establish or maintain the legitimacy of their actions and consequently to be seen as trustworthy individuals. Institutional theorists have shown numerous ways in which adherence to widely shared beliefs, widely accepted norms, formal rules and procedures can enhance trust. The driving force behind these methods can be explained most succinctly as 'the logic of appropriateness'. When managers wish to preserve or enhance trust in themselves or their institution, they often attempt to influence perceived choice appropriateness, which is judged not merely on contextual criteria of technical effectiveness, but also on what is expected and viewed as legitimate in a particular context.

In [19], the focus is on structural isomorphism or the use of standardized structure, procedures and actions as indicators of trust building, legitimacy-driven behavior. In a leader-subordinate relationship, the leader as a decision maker can institutionalize their decision in order to build trustworthiness. They argue that control as a legitimate power from a leader must be legitimized and institutionalized in order to enhance trust.

In addition, Dwyer and Beauvais [15] propose some principles based on institutional theory that can be used by organizations to build, enhance and maintain trust in a leader - follower relationship. They argue that, although trust is complex both in its composition and in terms of the number of bases on which is rests, the following principles when institutionalized within an organization would enable the organization to enhance levels of both trust and organizational success. The authors then conclude that building and maintaining trust within an organization is not a simple or rapid process. It requires a commitment to creating and sustaining a culture that is focused and respectful of employees. Unlike organizations that only talk about values, organizations that institutionalize the value or principles of trust will build trust in process and promote trust as an important element in the building of a successful organization.

Pucetaite and Lamsa [12] also argue that the development of trust within an organization can be stimulated by raising the level of work ethic through organizational practice. They explain that work ethics are moral principles, norms and rules that guide a person's behavior at work. Moreover, work ethics play a role as principles, particularly regarding compliance with quality standards, self-discipline and commitment to professional norms and the job itself. Accordingly, the idea of enhancing work ethics, as a consequence of management practices that are institutionalized and legitimized by an organization, is a particularly interesting means of developing trust.

\section{E. Control Theory Approach}

This approach suggests that managers who build trust often reduce the time and effort needed to measure and monitor the work of their employees, while enhancing the quality of their subordinate's contributions and their capacity to achieve organizational objectives. This control theory is based on the notion that managers integrate their trust-based and control-based actions in ways they think appropriate for specific situations. This theory also argues 
that managers should actively concern themselves with promoting organizational trust by combining with task control activities that are appropriate for the task and relational context, thereby ensuring that organizational goals are accomplished and positive superior subordinate relationships are developed and maintained.
Moreover, in order to address the dynamic nature of relational and institutional arrangements, managers must balance the mix of trust and control in their organization if they want to achieve organizational goals and cultivate positive social relationships.

\section{TABLE 1. THEORETICAL APPROACHES IN TRUST MAINTENANCE RESEARCH}

\begin{tabular}{|c|c|c|c|c|c|c|c|}
\hline No. & Author (s) & Use of term (s) & Theoretical Approach & Dimensio & f Model $f$ & ust Maintenance & Type of Relationship \\
\hline & & & & Practices & Policies & Methodology & \\
\hline 1. & [10] & $\begin{array}{l}\text { Building, } \\
\text { Maintaining } \\
\text { Enhancing }\end{array}$ & $\begin{array}{l}\text { Relational Signaling } \\
\text { Theory (RST) }\end{array}$ & $\mathrm{v}$ & $\mathrm{v}$ & $\mathrm{x}$ & $\begin{array}{l}\text { Leader - subordinate, and } \\
\text { Co-worker }\end{array}$ \\
\hline 2. & [12] & Developing & Exchange & $\mathrm{v}$ & $\mathrm{x}$ & $\mathrm{x}$ & $\begin{array}{l}\text { Leader - subordinate, and } \\
\text { Co-worker }\end{array}$ \\
\hline 3. & [14] & $\begin{array}{l}\text { Building } \\
\text { Maintaining }\end{array}$ & & $\mathrm{v}$ & $\mathrm{x}$ & $\mathrm{x}$ & Co-worker Relationship \\
\hline 4. & [11] & Building & RST & $\mathrm{x}$ & $\mathrm{v}$ & $\mathrm{x}$ & Leader - Subordinate \\
\hline 5. & [18] & Enhancing & $\begin{array}{l}\text { Organizational } \\
\text { Justice Theory }\end{array}$ & $\mathrm{x}$ & $\mathrm{v}$ & $\mathrm{x}$ & $\begin{array}{l}\text { Leader - Subordinate, and } \\
\text { Co-worker Relationship }\end{array}$ \\
\hline 6. & [15] & $\begin{array}{l}\text { Building } \\
\text { Enhancing } \\
\text { Maintaining }\end{array}$ & Institutional Theory & $\mathrm{x}$ & $\mathrm{v}$ & $\mathrm{x}$ & Leader - subordinate Relationship \\
\hline 7. & [21] & $\begin{array}{l}\text { Developing } \\
\text { Trust }\end{array}$ & Procedural Approach & $\mathrm{v}$ & $\mathrm{x}$ & $\mathrm{x}$ & Co-worker Relationship \\
\hline 8. & [20] & Building Trust & Control Theory & $\mathrm{v}$ & $\mathrm{x}$ & $\mathrm{x}$ & Leader - Subordinate Relationship \\
\hline 9. & [13] & $\begin{array}{l}\text { Building } \\
\text { Maintaining }\end{array}$ & RST in Leadership & $\mathrm{x}$ & $\mathrm{x}$ & $\mathrm{x}$ & Leader - Subordinate Relationship \\
\hline 10. & [19] & Building Trust & $\begin{array}{l}\text { Institutional and } \\
\text { Control Theory }\end{array}$ & $\mathrm{v}$ & $\mathrm{v}$ & $\mathrm{x}$ & $\begin{array}{l}\text { Leader - Subordinate, and Co- } \\
\text { worker Relationship }\end{array}$ \\
\hline 11. & [2] & Engendering & Relational Theory & $\mathrm{v}$ & $\mathrm{v}$ & $\mathrm{x}$ & Manager-Subordinate \\
\hline 12. & [22] & $\begin{array}{l}\text { Building and } \\
\text { Developing }\end{array}$ & $\begin{array}{l}\text { Social Exchange } \\
\text { Theory (SET) }\end{array}$ & $\mathrm{v}$ & $\mathrm{x}$ & $\mathrm{x}$ & Team work based Relationship \\
\hline 13. & [16] & Developing & SET & $\mathrm{v}$ & $\mathrm{x}$ & $\mathrm{x}$ & Leader - Subordinate \\
\hline
\end{tabular}

Furthermore, Long and Sitkin [20] examine the ways by which managers balance their interpersonal trust-building and control-based efforts in order to maintain trust in subordinates. Their study focuses on describing task controls which range from formal mechanisms (written contracts, monetary incentives and surveillance), to informal mechanisms (values, norms and beliefs). Managers can use these mechanisms to direct subordinates toward the efficient completion of organizational tasks. There are various control applications for directing subordinate tasks: input controls, process controls and output controls. The purpose of input controls is to acquire a high quality employee through training and socialization to guide the selection and preparation of human and material production process. Process controls are a means of controlling subordinates' performance of tasks to ensure that they follow prescribed task production methods. Output controls measure the employees' outputs (or productivity) against established metrics to ensure that prescribed performance standards are met.

\section{INTEGRATIVE REVIEW AND DIRECTIONS FOR FUTURE RESEARCH}

In this section, we briefly discuss research in trust maintenance from the perspective of terminology used, theoretical approach, model offered, and type of relationship (table 1). It is observed that most studies use terms such as 'building', 'developing', and 'maintaining' synonymously. They do not distinguish between these activities. However, based on trust evolution theory, there are different phases and activities in the life cycle of organizational trust. Therefore, every stage or phase in trust evolution should have a different model or method.

In addition, there is no theoretical approach that specifically addresses ways to maintain the level of trust. Those theoretical approaches have argued can be use in the same way on to create, build, engender and maintain leadersubordinate trusting relationship. Further, the most commonly-used theoretical approach is a basic model concerned with maintaining trust based on the completion of organizational tasks. The Social Exchange and Relational Signaling theory approach is concerned with the vulnerability and reciprocity of both parties when sharing valuable resources in order to accomplish a task. Institutional theory focuses on the importance of institutionalized and 
legalized work ethics and the procedures and norms to be followed when undertaking organizational tasks. Control theory is concerned with measuring and controlling input, process and output of work performance. However, these theoretical approaches work separately as a basis for maintaining organizational trust, specifically in a work relationship. Further research is needed to provide a complete and comprehensive methodology for trust maintenance. We define methodology as a sequence of steps that can be used by trusting parties to maintain their trust levels in a relationship.

We argue that future research into a methodology to maintain trust should incorporate some of these theoretical approaches in an integrative framework. We also note some basic assumptions for trust maintenance activities that may be derived from these theoretical approaches. Firstly, both parties (trusting agent and trusted agent) are vulnerable to reciprocal action. This assumption concurs with the social exchange approach to maintain trust. In social exchange theory, both parties that are involved in a relationship are able to share valuable resources in order to achieve a mutually rewarding goal. The second assumption is that both parties agree to and demonstrate cooperative behavior in order to maintain their level of trust. This assumption correlates with the relational quality approach for maintaining trust in a relationship. The relational quality approach is one whereby parties exchange a positive signal to maintain the relationship and avoid a negative signal that can destroy a trusting relationship. The third assumption is that the level of trust has been reached to a positive high level. Once trust has been established and is at a positive level, it needs to be maintained at that level. When the level of trust is still fairly low or neutral, it needs to be developed or enhanced to a higher level.

\section{CONCLUSION}

In this paper, we have presented a brief review in the field of trust maintenance research. We considered and summarized, from the existing literature, five theoretical approaches for maintaining trust. We reviewed these researches based on the terminology used, theoretical approach, model offered, and type of work relationship described. Evidently, substantial work has been done on trust maintenance, but the concept of trust maintenance itself has not been properly defined. Additionally, there are some existing good management practices and policies or principles for maintaining trust in an organizational setting. However, there is as yet no comprehensive and coherent methodology for trust maintenance.

\section{REFERENCES}

1. Langfield-Smith, K. and D. Smith, "Management control systems and trust in outsourcing relationships". Management Accounting Research, 2003. 14: p. 281-307.

2. Ferres, N., J. Connell, and A. Travaglione, "Coworker trust as a social catalyst for constructive employee attitudes". Journal of Managerial Psychology, 2004. 19(6).
3. Babar, M.A., J.M. Verner, and P.T. Nguyen, "Establishing and maintaining trust in software outsourcing relationship: an empirical investigation". The Journal of System and Software, 2007. 80 (1438 $-1449)$.

4. Currall, S.C. and M.J. Epstein, "The Fragility of Organizational Trust: Lessons From the Rise and Fall of Enron". Organizational Dynamics, 2003. 32(2): p. 193-206.

5. Blomqvist, K. and P. Ståhle, "Building organizational trust, in The 16th IMP Conference". 2000: Bath, UK,.

6. Chang, E., T. Dillon, and F. Hussain, "Trust and reputation for service-oriented environments: Technologies for building business intelligence and consumer confidence". 2006: John Wiley \& Sons.

7. Luna-Reyes, L.F., A.M. Cresswell, and G.P. Richardson, "Knowledge and the Development of Interpersonal Trust: a Dynamic Model", in Hawaii International Conference on System Science. 2004.

8. Hexmoor, H., S. Wilson, and S. Bhattaram, "A theoretical inter-organizational trust-based security model". The Knowledge Engineering Review, 2006. 21(2): p. 127-161.

9. Rousseau, D.M., et al., "Not So Different After All: A Cross Discipline View of Trust". Academy of Management Review, 1998. 23(3): p. 393-404.

10. Six, F. and A. Sorge, "Creating a High-Trust Organization: An Exploration into Organizational Policies that Stimulate Interpersonal Trust Building". Journal of Management Studies 2008. 45(5).

11. Six, F., E, "Building Interpersonal Trust within organizations: a relational signalling perspective". Journal Manage Governance, 2007. 11: p. 285-309.

12. Pucetaite, R. and A.-M. Lamsa, "Developing Organizational trust through advancement of employees' work ethic in a Post-Socialist Context". Journal of Business Ethics, 2008. 82: p. 325-337.

13. Dirks, K.T., ed. "Three Fundamental Questions regarding trust in leaders". Handbook of Trust Research, ed. R. Bachmann and A. Zaheer. 2006, Edward Elgar Publishing: Massachusetts.

14. Khalfan, M.M.A., P. McDermott, and W. Swan, "Building Trust in Construction Projects". Supply Chain Management: An International Journal, 2007. 12(6): p. 385-391.

15. Dwyer, R.J. and C. Beauvais, "Building and Maintaining Trust: The Essential Ingredient for Organizational Success". 2006.

16. Whitener, E.M., "The Impact of Human Resource Activities on Employee Trust". Human Resource Management Review, 1997. 7(4): p. 389-404.

17. Whitener, E.M., et al., "Manager as Initiators of Trust: An Exchange Relationship Framework for Understanding Managerial Trustworthy Behavior". Academy of Management Review, 1998. 23(3): p. 513-530.

18. Forret, M. and M.S. Love, "Employee justice perceptions and coworker relationship". Leadership \& Organizations Development Journal, 2007. 29(3): p. 248-260.

19. Sitkin, S.B. and E. George, "Managerial TrustBuilding through the use of legitimating formal and 
informal control mechanism”. International Sociology, 2005. 20(307).

20. Long, C.P. and S.B. Sitkin, eds. "Trust in the balance: how managers integrate trust-building and task control". Handbook of Trust Research, ed. R. Bachmann and A. Zaheer. 2006, Edward Elgar: Massachussetts.

21. Lamsa, A.-M. and R. Pucetaite, "Development of organizational trust among employees from a contextual perspective". Business Ethics: A European Review, 2006. 15(2).

22. Ferrin, D.L. and K.T. Dicks, "The use of rewards to increase and decrease trust: mediating processes and differential effects”. Organization Science, 2003. 14(1): p. $18-31$ 